\title{
2009/52
}

Regulating quality by regulating quantity: a case against minimum quality standards

Nicolas Boccard and Xavier Wauthy 
CORE

Voie du Roman Pays 34

B-1348 Louvain-la-Neuve, Belgium.

Tel (32 10) 474304

Fax (32 10) 474301

E-mail: corestat-library@uclouvain.be http://www.uclouvain.be/en-44508.html 


\title{
CORE DISCUSSION PAPER
}

$2009 / 52$

\section{Regulating quality by regulating quantity: a case against minimum quality standards}

\author{
Nicolas BOCCARD ${ }^{1}$ and Xavier WAUTHY ${ }^{2}$
}

\author{
September 2009
}

\begin{abstract}
We show in a simple model of entry with sunk cost, that a regulator prefers limiting the output, or capacity, of the incumbent firm rather than imposing a "Minimum Quality Standard" in order to help the entrant to provide high quality. As a by-product, our analysis makes a contribution to the study of Bertrand-Edgeworth competition in a market with differentiated products.
\end{abstract}

Keywords: quality, minimum quality standards, price competition.

JEL Classification: D43, L13, L51

\footnotetext{
${ }^{1}$ Departament d'Economia, University of Girona, Spain.

${ }^{2}$ Facultés universitaires Saint-Louis, CEREC, B-1000 Bruxelles, Belgium and Université catholique de Louvain, CORE, B-1348 Louvain-la-Neuve, Belgium.
}

Financial support from Ministerio de Educación y Ciencia (Programa Salvador de Madariaga) is gratefully acknowledged. The first author thanks the Center for Operations Research and Econometrics (CORE) for hosting him during the final stage of writing this paper.

This paper presents research results of the Belgian Program on Interuniversity Poles of Attraction initiated by the Belgian State, Prime Minister's Office, Science Policy Programming. The scientific responsibility is assumed by the authors. 



\section{Introduction}

The quality of products supplied by entrants is an important concern in those industries which have been subject to deregulation. While it is expected that an enhanced competition will ultimately materialize into lower consumers' prices, it is also hoped that this will not be detrimental to quality provision. Needless to say, incidents in the US electricity market (2001 California crisis, 2003 black-out) or UK railways (cf. Reuters news) suggest that quality might indeed be a concern. ${ }^{1}$ Anecdotal evidence from the broadband internet access also suggests that at the early stage, entrants tend to challenge the incumbent, most often the former monopoly which controls the telecommunication network, by offering lower prices for services which turn out to be of a lower quality (longer connection delays, limited reliability, limited technical support).

Quality provision may thus be a concern, even though consumers' high willingness to pay for quality should be a strong driver for competitive firms to constantly improve quality. Actually, Sheshinski (1976) has shown that the optimal quality selection by a monopolist rarely coincides with the efficient one, although the direction in which it departs is not always clear. In oligopolistic industries, a large literature starting with Gabszewicz and Thisse (1979) has shown the profitability of opting for a low quality when facing a high quality incumbent in order to relax market competition. From the regulator's point of view quality is also desirable as it reduces the impact of negative externalities (e.g., issues of pollution, safety or health). Coupled with a paternalistic attitude and the fear of market under-provision, there is a strong case for stepping-in and imposing Minimum Quality Standards (hereafter MQS).

As nicely demonstrated by Ronnen (1991), the adequate selection of a MQS can increase both quality and sales so that the industry welfare unambiguously increases. The intuition for this positive result is quite simple: by constraining the low quality firm to upgrade its quality, the MQS induces the high quality firm to select a higher quality (in order to relax competition). In equilibrium, the price competition is however fiercer so that prices are lower and more consumers end up participating. Crampes and Hollander (1995) establish a qualitatively similar result with a different costs structure.

These two papers obviously make a case for MQS but their conclusions might be challenged on several grounds. Firstly, Ronnen (1991)'s results in favor of imposing a MQS have formal validity only in a neighborhood of the unregulated level (cf. his theorem 5); the case for a significant policy change, the only one that a government may consider, is therefore poorly

\footnotetext{
${ }^{1}$ Evidences of the negative effect of deregulation in US Airline markets on the service quality can also be found in Rhoades and Waguespack (2000).
} 
supported. Next comes the issue of certification that inevitably goes along with MQS. ${ }^{2}$ In this respect, Albano and Lizzeri (2001) show that certification does not go without inefficiencies: although certification intermediaries tend to raise firms' incentives to provide quality, they are likely to fail in avoiding quality underprovision. Finally, the MQS instrument itself exhibits several drawbacks. Valletti (2000) shows that Ronnen (1991)'s mechanism is not robust to the mode of competition: the switch from Bertrand to Cournot type competition destroys the "good" incentives to increase qualities. Scarpa (1998) shows that the welfare enhancing effect might critically depend on the duopolistic structure of the industry. Maxwell (1998) puts MQS in a dynamic perspective and shows that they decrease welfare in the long run because they weaken incentives to innovate. Lutz et al. (2000) provide a model where firms may manipulate the selection of the MQS by the regulator in such a way that industry welfare actually decrease. Glass (2001) reaches similar conclusions in a slightly different setup. Interestingly enough, these cases against MQS are rooted in its most obvious implication: a MQS undermines industry's profitability. As a by-product, imposing a MQS might induce the exit of some firms, or reduce entry, a problem also acknowledged in Ronnen (1991) and Crampes and Hollander (1995). ${ }^{3}$

Building on the mixed appraisal of MQS reported above and, in particular, on the fact that a MQS might conflict with the possibility of entry in deregulated markets, alternative routes aimed at regulating quality might be explored. Although it is not that pervasive as a regulation policy, limiting the production capacity of the incumbent seems quite natural as a tool to invite entry since it ensures the entrant of a protected (though limited) market share. Actually, the current regulation framework in various European industries allows for such a regulation. An example is the italian electricity market where a new law prohibits any generation company from supplying more than one half of the national demand. This measure was successfully taken to induce entry of competitors to challenge the historical incumbent (former monopoly). A comparable provision can be found in the European Regulation on Deregulation of Public Transport whereby the regulator may choose to limit market coverage of an already dominant firm in order to allow for enough competition. More precisely, Article 9 states that "A competent authority may decide not to award public services contracts to any operator that already has or would, as a consequence, have more than a quarter of the value of the relevant market...". 4

\footnotetext{
${ }^{2}$ Regarding informational issues raised by quality provision in deregulated markets, we refer the reader to Auriol (1998).

${ }^{3}$ Notice that this mixed theoretical appraisal of MQS is to some extent confirmed by the (limited) empirical evidence. See in particular Chipty and Witte (1997) for a detailed empirical study of the effects of MQS on the quality of child care centers in the US.

${ }^{4}$ Amended proposal for a regulation of the European Parliament and of the council on action by member
} 
There is thus a case where capacity limitation may induce entry in a deregulated market. In the present paper, we show that such policies also have very nice complementarities regarding the regulation of quality provision. More precisely, we consider a stage game where the regulator (government) can either set a MQS or limit the output of the high quality incumbent firm. Then, the potential entrant selects quality and bears some sunk cost to enter; lastly firms compete in prices. Our (subgame perfect) equilibrium analysis reveals that in order to maximize industry welfare, the government should most often prefer the quantitative regulation over the MQS. The key feature of the quantitative restriction is to relax price competition so strongly in the last stage, that quality differentiation becomes purposeless. Accordingly, the entrant selects a high quality and because the entrant ends up making more profits in equilibrium, entry remains compatible with quality enhancement for a wider range of entry cost.

A second contribution of this paper consists in offering some original results regarding the outcomes of Bertrand-Edgeworth competition in markets with differentiated product. As is well-known, capacity constrained price competition has been widely studied in markets with homogeneous goods after the seminal paper of Kreps and Scheinkman (1983). By contrast, very few positive results exist for the case of differentiated goods. ${ }^{5}$ In this paper we offer additonal characterizations of firms' payoffs for such games which complements the earlier results of Krishna (1989) and Furth and Kovenock (1993). While these papers deal with horizontal differentiation, our paper is the first one to cast the problem in a setup with vertical differentiation. Our results should prove useful for further investigations on the nature of price competition in markets with capacity constrained firms and differentiated products.

\section{Premices}

We consider a regulator $R$, an incumbent firm $i$ and a potential entrant firm $e$ interacting in the stage game $\Gamma$ of Figure 1 to be analyzed using the concept of subgame perfect equilibrium (SPE). The regulator may adopt a "laissez-faire" (LF) attitude or be more active with either the enforcement of a minimum quality standard (MQS) (over the entrant) or the imposition of a sales restriction (SR) (over the incumbent). Each possible strategy gives rise to a subgame where the entrant has to decide whether to enter, and if so, pick a quality level before engaging into price competition with the incumbent.

states concerning public service requirements and the award of public sector contracts in passenger transport by rail, road and inland waterway, Official Journal of the European Commission, C 151 E/146-183, Article 9-2.

\footnotetext{
${ }^{5}$ Noticeable exceptions are Krishna (1989), Furth and Kovenock (1993) and Cabral et al. (1998)
} 


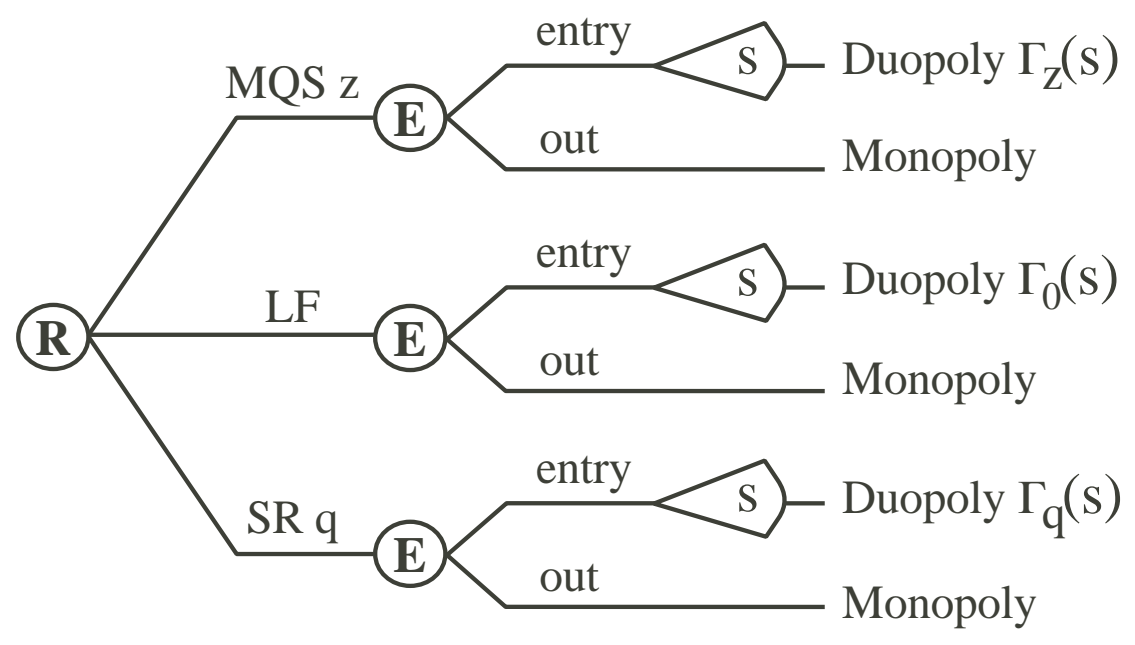

Figure 1: The stage game $\Gamma$

Section 2.1 presents the details of the model and solves the laisser-faire case. Section 2.2 characterizes the equilibrium under minimum quality standard and derives the preferred MQS of the regulator. Section 3 then brings the necessary modifications to study price competition under a binding capacity limit. We derive the optimal quality choice of the entrant and his optimal entry strategy conditional on the government imposed sales restriction (which affects directly only his competitor the incumbent). After characterizing the preferred quota for the regulator in section 3.5, we can in section 3.6 compare the three instruments and prove the claims enunced in the introduction. Section 4 concludes.

\section{1 "Laissez-Faire"}

The following hypothesis apply for the entire game $\Gamma$. To better focus on the relative merits of MQS and SR as regulatory instruments, we assume that quality is not costly for firms and that the marginal cost of production is nil. Secondly, in agreement with most observed real cases, the incumbent $i$ is committed to the best available quality (normalized to unity) ${ }^{6}$ so that the entrant $e$ cannot leapfrog him. In formulas, we set $s_{i}=1, F_{i}=0, s_{e}=s \in[0,1], F_{e}=F>0$.

In line with the literature on MQS, we follow Mussa and Rosen (1978) and (Tirole, 1988, sec. 2.1) to model quality differentiation. A consumer with personal characteristic $x$ is willing to pay $x s$ for one unit of quality $s$ and nothing more for additional units. He maximizes surplus and when indifferent between two products, select his purchase randomly. Types are

\footnotetext{
${ }^{6}$ An upper bound on the admissible qualities is required to ensure that firms' payoffs are bounded. We perform the analysis with the cost of quality $k(s)=\frac{s^{2}}{K}$ for $s \in[0,1]$ without notably affecting the qualitative conclusions of our analysis. The computations are available upon request from the authors. Notice that our cost assumption amounts to choose $K$ arbitrarily large.
} 
uniformly distributed in $[0 ; 1]$.

Under "Laissez-Faire" (subgame $\Gamma_{0}$ ), the challenger decides whether to enter or not, and if so, chooses her quality $s$ and pays a sunk cost $F \geq 0$. In the second stage, denoted $\Gamma_{0}(s)$, the two firms sell goods differentiated by their quality and compete in prices. We study Subgame Perfect Equilibria of $\Gamma_{0}$. We may characterize demands addressed to the firms as follows: whenever $s<1$

$$
\begin{aligned}
& D_{e}\left(p_{e}, p_{i}\right)=\left\{\begin{array}{lll}
1-\frac{p_{e}}{s} & \text { if } \quad p_{e} \leq p_{i}-1+s \\
\frac{p_{i} s-p_{e}}{s(1-s)} & \text { if } \quad p_{i}-1+s \leq p_{e} \leq p_{i} s \\
0 & \text { if } \quad p_{e} \geq p_{i} s
\end{array}\right. \\
& D_{i}\left(p_{e}, p_{i}\right)= \begin{cases}1-\frac{p_{i}}{1} & \text { if } p_{i} \leq \frac{p_{e}}{s} \\
1-\frac{p_{i}-p_{e}}{1-s} & \text { if } \frac{p_{e}}{s} \leq p_{i} \leq p_{e}+1-s \\
0 & \text { if } p_{i} \geq p_{e}+1-s .\end{cases}
\end{aligned}
$$

while for $s=1$ we have:

$$
D_{i}\left(p_{i}, p_{j}\right)=\left\{\begin{array}{lll}
1-p_{i} & \text { if } & p_{i}<p_{j} \\
\frac{1-p_{i}}{2} & \text { if } & p_{i}=p_{j} \\
0 & \text { if } & p_{i}>p_{j}
\end{array}\right.
$$

Firms' profits at the last stage of the game are

$$
\Pi_{e}\left(p_{i}, p_{e}\right)=p_{e} D_{e}\left(p_{i}, p_{e}\right) \quad \text { and } \quad \Pi_{i}\left(p_{i}, p_{e}\right)=p_{i} D_{i}\left(p_{i}, p_{e}\right)
$$

The characterization of Nash equilibria in the pricing game $\Gamma_{0}(s)$ is fairly straightforward. Consequently, we limit ourselves to an informal (and mainly graphical) argument. The payoffs are continuous and give rise to continuous best response functions illustrated on Figure 2. Notice in particular that the striped area characterizes the prices constellation for which both firms enjoy a positive demand.

Accordingly, the firms' best response are

$$
\psi_{e}\left(p_{i}\right)=\min \left\{\max \left\{\frac{p_{i} s}{2}, p_{i}+1-s\right\}, \frac{s}{2}\right\}
$$

and

$$
\psi_{i}\left(p_{e}\right)=\min \left\{\max \left\{\frac{1-s+p_{e}}{2}, \frac{p_{e}}{s}\right\}, \frac{1}{2}\right\}
$$

exhibit kinks when they hit their relevant non-negativity constraint. The unique price equilibrium given by the intersection of the best responses curves (5-6) is

$$
p_{e}^{*}=\frac{s(1-s)}{4-s} \quad \text { and } \quad p_{i}^{*}=\frac{2(1-s)}{4-s}
$$




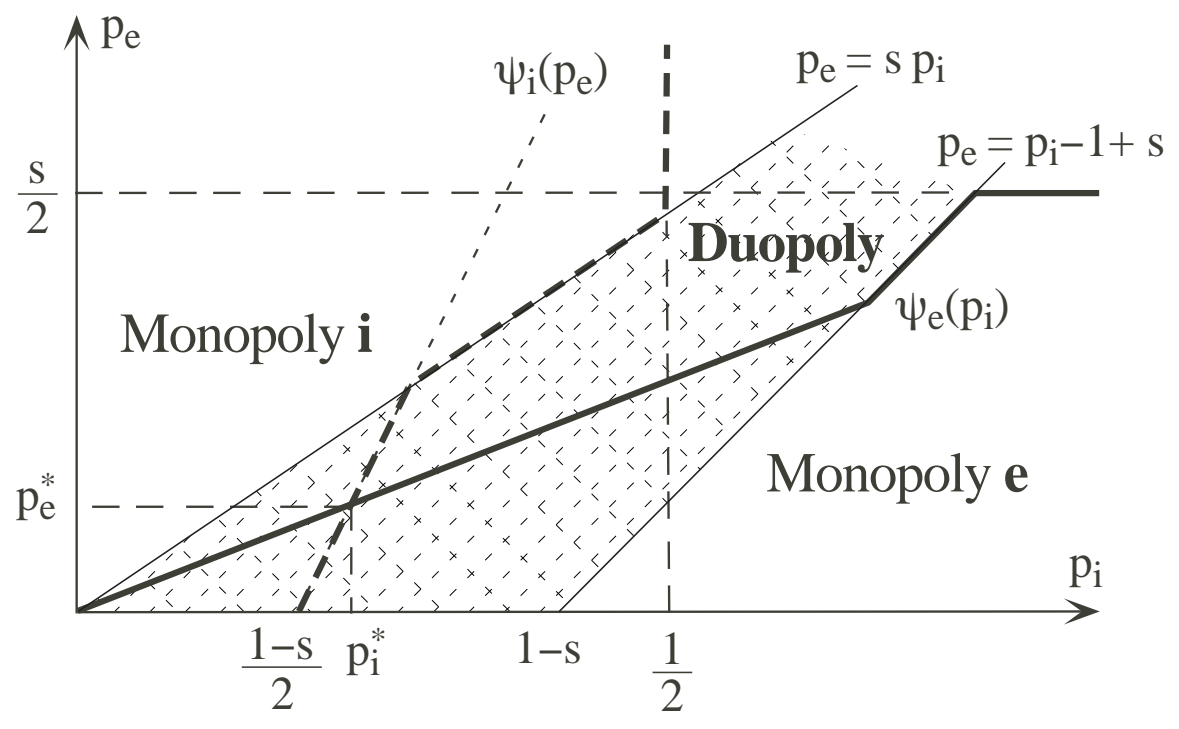

Figure 2: The price space

Plugging (7) into (4), we obtain the first stage payoffs as a function of the entrant's quality

$$
\Pi_{i}=\frac{4(1-s)}{(4-s)^{2}} \quad \text { and } \quad \Pi_{e}=\frac{s(1-s)}{(4-s)^{2}}
$$

The subgame perfect equilibrium (in pure strategies) of the "Laissez-Faire" game $\Gamma_{0}$ is characterized by Choi and Shin (1992). Practically, the entrant's optimal choice solution of $\frac{\partial \Pi_{e}}{\partial s}=0$ is $s=\frac{4}{7}$, leading to a payoff of $\frac{1}{48}$ in equilibrium. Accordingly, entry will take place if only $F \leq \frac{1}{48}$. The "Laissez-Faire" analysis is summarized in the next Lemma.

Lemma 1 Suppose quality is not costly and the incumbent sells quality $s_{i}=1$, then whenever $F \leq \frac{1}{48}$, the entrant enters and optimally differentiates by selecting quality $s=\frac{4}{7}$. The price equilibrium of the continuation game is unique and in pure strategies.

For later use, we notice that equilibrium sales are $D_{i}^{*}=\frac{7}{12}$ and $D_{e}^{*}=\frac{7}{24}$ i.e., the incumbent sells twice as much as the entrant.

\subsection{Minimum Quality Standard}

In this section, the government commits to a minimum quality standard (MQS) $0 \leq z \leq 1$ (since the MQS cannot supersede the best available quality). The continuation game played by the two firms is denoted $\Gamma_{z}$.

Consider the case where the challenger has entered the market. Obviously, a MQS lower than the laisser-faire equilibrium level $\frac{4}{7}$ leaves the entrant unbothered whereas a greater level 
leads him to stick to the lowest admissible quality level $z$. Following standard analysis, the resulting price equilibrium is

$$
p_{e}^{z}=\frac{z(1-z)}{4-z}, p_{i}^{z}=\frac{2(1-z)}{4-z},
$$

leading to demands $D_{i}^{z}=2 D_{e}^{z}=\frac{2}{4-z}$ and equilibrium profits

$$
\Pi_{e}^{z}=\frac{z(1-z)}{(4-z)^{2}}, \Pi_{i}^{z}=\frac{4(1-z)}{(4-z)^{2}} .
$$

To characterize the optimal MQS for the regulator, we assume that her objective is to maximize market welfare and that the enforcement costs of a MQS are nil. Net of the sunk entry cost $F$, welfare is

$$
\underline{W}(z)=\int_{1-D_{i}^{z}}^{1}\left(x-p_{i}^{z}\right) d x+\int_{1-D_{e}^{z}-D_{i}^{z}}^{1-D_{i}^{z}}\left(z x-p_{e}^{z}\right) d x+\Pi_{i}^{z}+\Pi_{e}^{z}=\frac{12-z-2 z^{2}}{2(4-z)^{2}}
$$

where the first two terms denote the surplus of consumers buying the high and low quality product respectively. This function is increasing and concave in $z .^{7}$ Notice that $\underline{W}(z)$ ranges from $\frac{3}{8}$ to $\frac{1}{2}$ over the range $[0,1]$.

Incidentally, $\underline{W}(1)=\frac{1}{2}$ also defines the first best for this industry, when there are no entry sunk cost. This quite intuitive result corresponds to the case where all consumers buy the best available quality at marginal cost (which is zero in the present case). This outcome would be achieved if there were two firms in the market, competing in price with an homogeneous product of top quality $s=1$. Since firms derive no economic rent in this equilibrium, entry takes place only if the fixed cost for quality $F$ is nil i.e., the long term "free entry" hypothesis of perfect competition holds. Given that the later hypothesis is untenable, we are forced to place our study in a second best world. ${ }^{8}$

The regulator must therefore distinguish whether entry occurs or not as a consequence of her choice of the MQS z. In absence of entry, the top quality monopoly incumbent serves half of the market at the monopoly price $p^{M}=\frac{1}{2}$ and generates a welfare of $\frac{3}{8}$, incidentally equal to $\underline{W}(0)$. In case of entry, welfare is $\underline{W}(z)$ and since this is an increasing function, the preferred choice of the regulator is the maximal MQS compatible with entry.

There is indeed a tension between a MQS and entry because the higher the MQS, the closer the two versions of the product, the tougher the price competition and the lower the

\footnotetext{
${ }^{7}$ We have $\underline{W^{\prime \prime}}(z)=-\frac{17 z+4}{(4-z)^{4}}<0<\underline{W^{\prime}(z)}=\frac{20-17 z}{2(4-z)^{3}}$.

${ }^{8} \mathrm{We}$ do not consider subsidies to foster entry as they are increasingly fought against by higher order regulation authorities such as the WTO or the European Commission. Recall that the necessary monetary transfers involved have distortionary effect on the economy and generate costly information asymmetries between the government and the candidate firm.
} 
entrant's profits which are necessary to recoup the entry sunk cost. As a consequence, the positive entry cost $F$ determines the maximum MQS that can be successfully implemented. Formally, we may summarize the previous argument in the following Lemma.

Proposition 1 Whatever the fixed cost $F$ in $\left[0 ; \frac{1}{48}\right]$, there exists an optimal MQS $z^{*}(F)$ that guarantees entry of the challenger. Both $z^{*}(F)$ and $\underline{W}\left(z^{*}(F)\right)$ decrease with $F$.

Proof: The upper bound for the MQS is given by the level $z^{*}(F)$ for which an entrant's profit, net of the entry cost is zero. Solving for $\Pi_{e}^{z}=F$, we obtain $z^{*}(F)=\frac{1+8 F+\sqrt{1-48 F}}{2(1+F)}$, as the unique relevant root (with $z^{*}(0)=1$ as expected). As $z^{* \prime}(F)=\frac{24 F+7 \sqrt{1-48 F}-25}{2 \sqrt{1-48 F}(1+F)^{2}}<0 \Leftrightarrow$ $576(1+F)^{2}>0$, this function is decreasing over the domain $F \in\left[0, \frac{1}{48}\right]$ and since $\underline{W}($.$) is$ increasing, total welfare is a decreasing function of the sunk cost over $\left[0, \frac{1}{48}\right]$.

Corollary 1 When $F$ increases from 0 to $\frac{1}{48}$, the duopoly regime prevails; the net surplus $\underline{W}\left(z^{*}(F)\right)-F$ is concave decreasing with limit $\frac{7}{16} \simeq 0.437$. For $F>\frac{1}{48}$, the monopoly regime prevails and welfare drops to $\frac{3}{8}=0.375$.

\section{Sales Restriction}

In this section, the regulator imposes a sales restriction $q$ upon the incumbent which defines the game $\Gamma_{q}$ played by firms. Such a sales' restriction or quota can be implemented by controling firms' production capacities through the limited emission of construction permits or by editing new regulations.

\subsection{Price Competition with a Quantitative Restraint}

By definition, the sales quota $q$ defines the largest demand level the incumbent is allowed to serve. This restriction deeply alters the nature of competition in the pricing game $\Gamma_{q}(s)$.

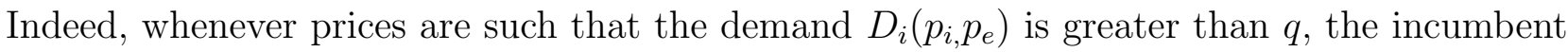
must turn $D_{i}\left(p_{i}, p_{e}\right)-q$ consumers away in order to comply with the sales restriction. In other words, the incumbent rations consumers when demand addressed to him exceeds the quota. The key implication of the sales restriction is thus to induce Bertrand-Edgeworth competition at the pricing stage of the game. As is well-known, the organization of rationing in the market is a critical issue for such games. ${ }^{9}$ We assume that the efficient rationing rule is at work i.e.,

\footnotetext{
${ }^{9}$ See Davidson and Deneckere (1986) for a classical analysis of this last issue.
} 
whenever $D_{i}\left(p_{i}, p_{e}\right)>q$, rationed consumers are those who exhibit the lowest willingness to pay for the good.

We now turn to the analysis of the pricing subgames. Two classes of Bertrand-Edgeworth pricing games have to be distinguished according to the quality selected in the first stage:

- If $s=1$, firms sell homogeneous products in the price game and one of them faces a quantitative constraint. We shall refer to Levitan and Shubik (1972) for a detailed analysis of the price equilibrium in these subgames.

- If $s<1$, we have a Bertrand-Edgeworth pricing game with product differentiation. We present an original characterization of equilibrium payoffs for such games. ${ }^{10}$

We start by analyzing subgames where products are differentiated $(s<1)$ and then pass to the case of homogeneous products before concluding with the optimal quality choice by the entrant.

\subsection{Differentiated Products}

We study the pricing game $\Gamma_{q}(s)$ for $s_{e}=s<1=s_{i}$. We divide the price space into a binding and competitive regime according to whether the sales constraint is active or not. Under efficient rationing, when a consumer wishes to buy the high quality product but is rationed by the incumbent, he always prefers to buy the low quality product of the entrant rather than not consuming. Thus, when at the prevailing prices the demand addressed to the incumbent exceeds the quota $q$, all rationed consumers are recovered by the entrant which faces a residual market $1-q$.

Using the demand equation (2), we derive the solution of $D_{i}\left(p_{e}, p_{i}\right)=q$ as $p_{i}=\beta^{-1}\left(p_{e}\right) \equiv$ $\min \left\{1-q, p_{e}+(1-q)(1-s)\right\}$ which a non decreasing function. The sales of both firms are therefore

$$
S_{i}\left(p_{e}, p_{i}\right)= \begin{cases}D_{i}\left(p_{e}, p_{i}\right) & \text { if } p_{e} \leq \beta\left(p_{i}\right) \\ q & \text { if } p_{e} \geq \beta\left(p_{i}\right)\end{cases}
$$

and

$$
S_{e}\left(p_{e}, p_{i}\right)=\left\{\begin{array}{lll}
D_{e}\left(p_{e}, p_{i}\right) & \text { if } & p_{e} \leq \beta\left(p_{i}\right) \\
1-q-\frac{p_{e}}{s} & \text { if } & p_{e} \geq \beta\left(p_{i}\right)
\end{array}\right.
$$

Notice, as a preliminary observation, that within the binding domain, the incumbent's sales are constant so that the optimal price is simply the highest price for which the quota

\footnotetext{
${ }^{10}$ Furth and Kovenock (1993) also provide some characterization of equilibrium payoffs in BertrandEdgeworth games of horizontal product differentiation with sequential pricing decisions.
} 
is binding. As for the entrant, he holds a monopoly over a protected market of size $1-q$ so that his optimal price is also independent of the incumbent's one. The keypoint then is to note that the possibility of rationing breaks the concavity of the entrant's profit function whereas that of the incumbent's remains concave but only over the domain where his demand is positive (recall from $(2)$ that $D_{i}$ becomes nil for $p_{i}>p_{e}+1-s$ ).

This phenomenon will preclude the existence of pure strategy equilibria in many pricing subgames. While the existence of mixed strategy equilibria is not an issue here because of the continuity in payoffs, the characterization of mixed strategy equilibria in BertrandEdgeworth games with product differentiation is to a large extent an open problem. To the best of our knowledge, Krishna (1989) provides the first characterization of a mixed strategy equilibrium in a model of symmetric product differnetiation. The structure of the mixed strategy equilibrium she identifies can be used within our setup. It takes the following form: the entrant will mix over two atoms (the security price and some lower price) while the incumbent will play a pure strategy. However, in many subgames, this equilibrium does not exist because a crucial non-negativity constraint is not satisfied for the incumbent. While we do not characterize equilibria explicitely, we are able to characterize the entrant's equilibrium payoff for such cases.

The following proposition constitutes the technical contribution of this article to the literature on Bertrand-Edgeworth competition with product differentiation.

Proposition 2 Assume $s<s_{i}=1$, there exists a critical value for the quota $\bar{q}(s)$ such that

- if $q>\bar{q}(s)$, the "Laissez-Faire" equilibrium prevails.

- if $q \leq \bar{q}(s)$, there exists no pure strategy equilibrium and in any mixed strategy equilibirum the entrant obtains the security payoff $\frac{1}{4} s(1-q)^{2}$.

Proof We proceed through four steps. Firstly, we derive firms' best reponse. Secondly, we identify the range in which the "Laissez-Faire" equilibrium analysis still applies. Thirdly, we characterize a mixed strategy equilibrium where only the entrant firm mixes over two atoms and characterize the associated payoffs. Finally, when the quota is tight, the former mixed strategies equilibrium fails to exist but we are able to prove that in any equilibrium (involving non-degenerated mixed strategies for the two firms) the entrant nets his the security payoff.

Step 1 It is clear from eq. (10) that the best response of the incumbent over the binding regime is the largest available price $\beta^{-1}\left(p_{e}\right)$. Using the continuity of payoffs, itself a consequence of demand continuity, we note that this optimal price is weakly dominated by the best response of the competitive (non binding) regime. The candidate best reply in that regime has been previously characterized as $\psi_{i}\left(p_{e}\right)=\frac{p_{e}+1-s}{2}$, so that whenever this later price belongs to the 
competitive regime, it is the best reply of the incumbent. Formally, we obtain the best response

$$
\phi_{i}\left(p_{e}\right)= \begin{cases}\psi_{i}\left(p_{e}\right) & \text { if } p_{e} \leq \bar{p}_{e} \\ \beta^{-1}\left(p_{e}\right) & \text { if } \quad p_{e} \geq \bar{p}_{e}\end{cases}
$$

where $\bar{p}_{e} \equiv \max \{0,(2 q-1)(1-s)\}$ solves $\psi_{i}\left(p_{e}\right)=\beta^{-1}\left(p_{e}\right)$. The best response of the incumbent is displayed on Figure 4 in dotted bold face; it is continuous with a kink at $\bar{p}_{e}{ }^{11}$ The non negativity constraint (NNC) $S_{i}=D_{i}=0$ displayed on Figure 4 is defined by equation $p_{i}=$ $p_{e}+1-s$.

In the binding regime, the entrant benefits from a monopoly position over a protected market of size $1-q$, his profit is $\pi_{e}=\left(1-q-\frac{p_{e}}{s_{e}}\right) p_{e}$ and reaches a maximum of $\Pi_{e}(q, s) \equiv \frac{s(1-q)^{2}}{4}$ at the security price $p_{e}^{s} \equiv \frac{(1-q) s}{2}$. In the competitive regime, the best response candidate is the unregulated candidate $\psi_{e}\left(p_{i}\right)=\frac{p_{i} s}{2}$. The associated payoff is $\Pi_{e}\left(\psi_{e}\left(p_{i}\right), p_{i}\right)=\frac{s p_{i}^{2}}{4(1-s)}$ which is increasing in $p_{i}$. It then remains to solve

$$
\Pi_{e}(q, s)=\frac{s p_{i}^{2}}{4(1-s)} \Leftrightarrow p_{i}=\mu(q, s) \equiv(1-q) \sqrt{1-s}
$$

in order to obtain the entrant's best response correspondence: ${ }^{12}$

$$
\phi_{e}\left(p_{i}\right)= \begin{cases}p_{e}^{s} & \text { if } \quad p_{i} \leq \mu(q, s) \\ \psi_{e}\left(p_{i}\right) & \text { if } \quad p_{i} \geq \mu(q, s)\end{cases}
$$

Step 2: Since $\phi_{e}($.$) is discontinuous at \mu(q, s)$, the existence of a pure strategy equilibrium is not ensured. There are however four pure strategy candidates corresponding to the combinations "binding" and "competitive" among the two firms.

Firstly, we have the "Laissez-Faire" equilibrium $\left(p_{i}^{*}, p_{e}^{*}\right)$ where both firms are in the competitive regime; it is indeed an equilibrium if $p_{i}^{*}>\mu(q, s) \Leftrightarrow q>\bar{q}(s) \equiv 1-\frac{2 \sqrt{1-s}}{4-s}$ (contrary to what is shown on Figure 3).

The second candidate is when the entrant is in the competitive regime while the incumbent sells at the quota level; it is the intersection of $\psi_{e}\left(p_{i}\right)$ and $\beta^{-1}\left(p_{e}\right)$ at $\hat{p}_{i}=2(1-q) \frac{1-s}{2-s}$. However this is not a valid candidate because one can check that $\hat{p}_{i}<\mu$ holds true, thus the relevant branch of the best reply $\phi_{e}\left(p_{i}\right)$ is actually $p_{e}^{s}$. The other two candidates for a pure strategy equilibrium are when the horizontal line at $p_{e}^{s}$ crosses either $\beta^{-1}($.$) or \phi_{i}($.$) ; both can be$ dismissed because the jump at $\mu$ will always occur inside the binding area i.e., before the intersection.

\footnotetext{
${ }^{11}$ The $\beta^{-1}$ line crosses the frontier between duopoly and monopoly for the incumbent at $p_{i}=1-q$ and $p_{e}=s(1-q)=2 p_{e}^{s}$; for larger $p_{e}$ it becomes a vertical.

${ }^{12} \phi_{e}$ is single valued except at $\mu(q, s)$ where it admits two values.
} 


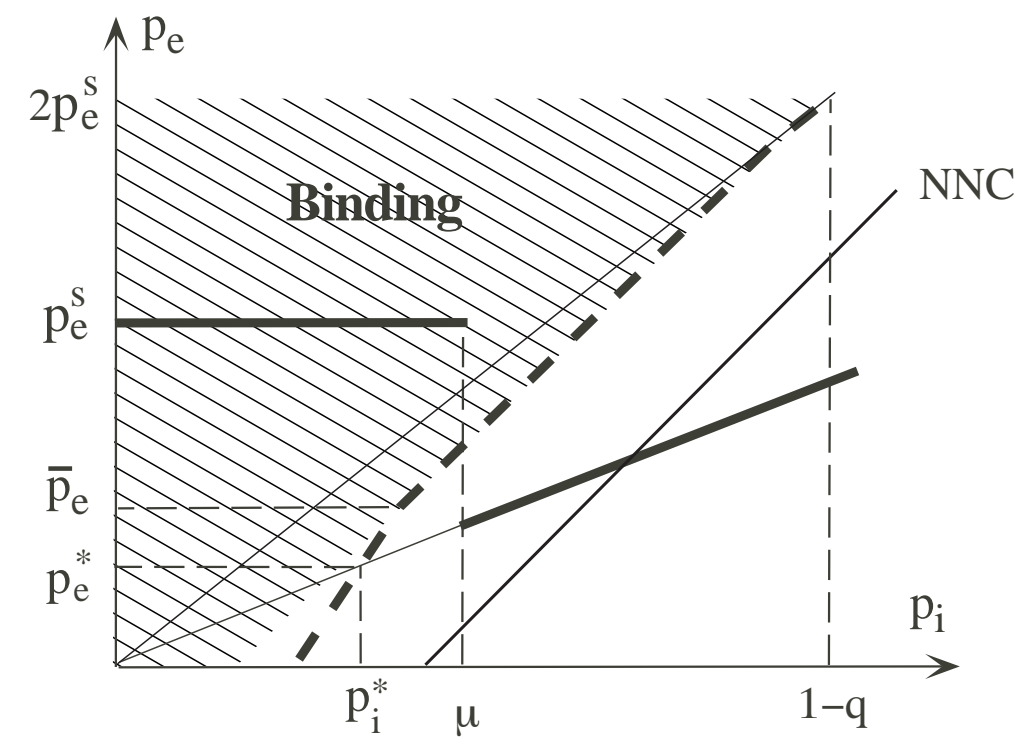

Figure 3: The price space with quota

Step 3: Suppose $q<\bar{q}(s)$. As illustrated on Figure 3, there exists no pure strategies equilibrium. A natural candidate is proposed by Krishna (1989): the incumbent plays the pure strategy $\mu(q, s)$ and the entrant randomizes over the pair of prices $p_{e}^{s}$ and $\psi_{e}(\mu(q, s))$. By definition of $\mu$, the entrant is indifferent between $p_{e}^{s}$ and $\psi_{e}(\mu(q, s))$; any mixture over these two prices yields the same payoff. We now compute the weights that make $\mu$ a best response for the incumbent.

Let $\alpha$ be the weight on $p_{e}^{s}$. When facing $p_{e}^{s}$, the sales of firm $i$ are $S_{i}=q$ while they are $S_{i}=1-\frac{p_{i}-\psi_{e}(\mu)}{1-s}$ when facing $\psi_{e}(\mu)$. The expected profit is thus

$$
\pi_{i}=p_{i}\left[\alpha q+(1-\alpha)\left(1-\frac{p_{i}-\psi_{e}(\mu)}{1-s}\right)\right]
$$

and is maximum when $\alpha q+(1-\alpha)\left(1-\frac{2 p_{i}-\psi_{e}(\mu)}{1-s}\right)=0$ i.e., for

$$
p_{i}=\frac{\psi_{e}(\mu)}{2}+\frac{1-s}{2}\left(\frac{\alpha q}{1-\alpha}+1\right)=\frac{\mu s}{4}+\frac{1-s}{2}\left(\frac{\alpha q}{1-\alpha}+1\right)
$$

Now, in equilibrium, $\alpha$ is such that this best reply is exactly $\mu$ hence

$$
\alpha=\frac{\frac{\mu}{2}\left(\frac{4-s}{1-s}\right)-1}{\frac{\mu}{2}\left(\frac{4-s}{1-s}\right)-1+q}<1 .
$$

Observe that $\alpha>0 \Leftrightarrow(4-s)(1-q) \sqrt{1-s}>2(1-s) \Leftrightarrow q<\bar{q}(s)$ which is true in the present case. A necessary condition for this equilibrium to exist is that $D_{i}\left(\mu, \psi_{e}(\mu)\right)>0$, i.e. the incumbent receives a positive demand for otherwise he would reduce his price to 
get some demand and some profit. Solving this inequality for $q$, we obtain the restriction $q>\underline{q}(s) \equiv 1-\frac{2 \sqrt{1-s}}{2-s}$.

The entrant's equilibrium profit can be computed at any of the prices in the support of his strategy, for instance at the security price $p_{e}^{s}$ where his payoff is already known to be $\Pi_{e}(q, s) \equiv \frac{s(1-q)^{2}}{4}$ (because it is independent of the incumbent's behavior).

Step 4 We show that for $q \leq \underline{q}(s)$, in every mixed strategy equilibrium, the entrant earns $\Pi_{e}(q, s)$. Figure 4 depicts a configuration where the non-negativity constraint (NNC) is binding for the mixed strategy equilibrium candidate identified in Step 3. Recall that the frontier between the binding and non-binding quota regimes is identified with $\beta($.$) . Best responses$ are drawn in bold face. For $j=i, e$, we denote by $F_{j}$ the firm $j$ 's mixed strategy in a Nash equilibrium.

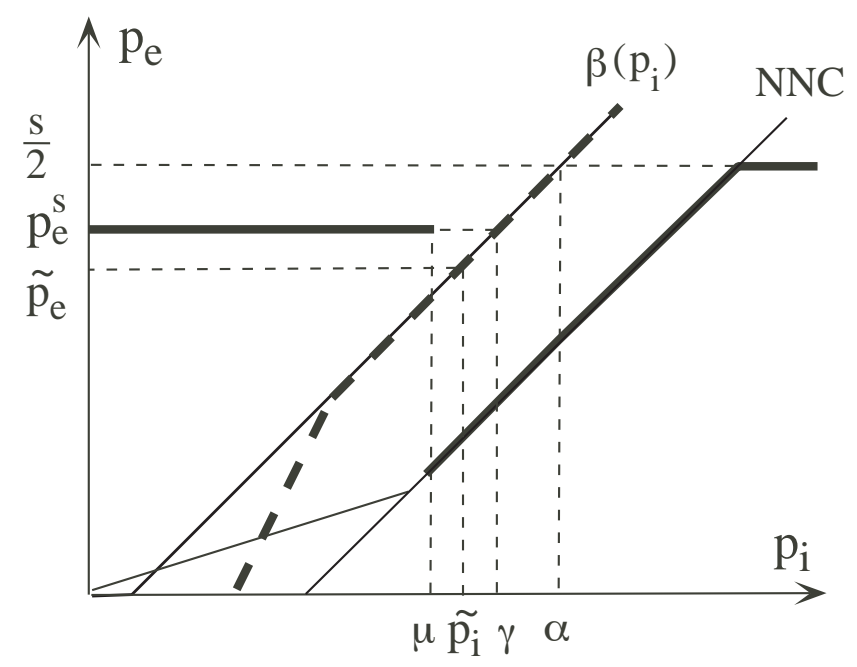

Figure 4: Best responses in prices

We first show that players supports are quite limited. Observe that, by construction of the best response, the entrant's profit is decreasing in own price over $\left[\frac{s}{2}, 1\right]$ whatever $p_{i}$ may be. Hence, $\Pi_{e}\left(p_{e}, F_{i}\right)=\int \Pi_{e}\left(p_{e}, p_{i}\right) d F_{i}\left(p_{i}\right)$, the average over $F_{i}$ is likewise decreasing over the same range so that the support of $F_{e}$ has to be included in $\left[0, \frac{s}{2}\right]$. For $p_{e} \in\left[0, \frac{s}{2}\right]$, the incumbent's profit is decreasing in own price over $[\alpha, 1]$, hence the average over $F_{e}$ is likewise decreasing over the same range so that the support of $F_{i}$ is included in $[0, \alpha]$. For $p_{i} \in[0, \alpha]$, the entrant's profit is decreasing in own price over $\left[p_{e}^{s}, \frac{s}{2}\right]$ (because he needs not consider the area on the right of the NNC), hence the average over $F_{i}$ is likewise decreasing over the same range so that the support of $F_{e}$ is included in $\left[0, p_{e}^{s}\right]$. By the same token the support of $F_{i}$ is included in $[0 ; \gamma]$.

Let $\tilde{p}_{e}$ be the supremum of the support of $F_{e}$ and $\tilde{p}_{i}=\beta^{-1}\left(\tilde{p}_{e}\right)$. We claim that $\tilde{p}_{e}=p_{e}^{s}$. If 
not, the previous reasoning applies again telling us that $\Pi_{i}$ is decreasing over $\left[\tilde{p}_{i}, \gamma\right]$ for every $p_{e} \in\left[0, \tilde{p}_{e}\right]$, hence the incumbent does not play prices above $\tilde{p}_{i}$ in equilibrium. Now recall that in a mixed strategy equilibrium the payoff of a player can be computed at any of the prices belonging to the support of his optimal strategy; let us then consider $\tilde{p}_{e}$ for the entrant. For any $p_{i} \in\left[0, \tilde{p}_{i}\right]$, the incumbent is constrained by the quota so that the entrant is a monopoly over a market of size $1-q$, hence her optimal behavior is to try to reach the price $p_{e}^{s}$. This stands in contradiction to the fact that $\tilde{p}_{e}$ is the highest optimal price. We have thus proven that $\tilde{p}_{e}=p_{e}^{s}$ and as a consequence that the equilibrium payoff is $\Pi_{e}\left(\tilde{p}_{e}, F_{i}\right)=\frac{s}{4}(1-q)^{2}$ since the support of $F_{i}$ is included in $[0 ; \gamma]$.

\subsection{Homogeneous Products}

We analyze here the equilibrium of the pricing subgame where firms sell identical top qualities $(s=1)$. In this case, the vertical differentiation model degenerates into a standard BertrandEdgeworth duopoly over the demand $D(p)=1-p$, but with a quantity constraint $q$ for one firm. Levitan and Shubik (1972) study such a game under efficient rationing. Defining $\lambda(q) \equiv \frac{1-\sqrt{q(2-q)}}{2}$, they show:

Lemma 2 In a Nash equilibrium of the pricing game where $s_{i}=s=1$, firms play a mixed strategy with common support $\left[\lambda(q), \frac{1-q}{2}\right]$ and cumulative distributions $F_{e}(p)=1-\frac{\lambda(q)}{p}$ and $F_{i}(p)=\frac{p(1-p)-\lambda(q)(1-\lambda(q))}{p q}$.

Observe that $F_{i}(\lambda(q))=0, F_{i}\left(\frac{1-q}{2}\right)=1, F_{e}(\lambda(q))=0$ and $F_{e}\left(\frac{1-q}{2}\right)<1$, thus only the entrant has an atom at the upper price $\frac{1-q}{2}$. In this equilibrium, the incumbent's profit is $\Pi_{i}(q)=q \lambda(q)$ since at his lowest price he gets the whole demand $1-\lambda(q)$ thus sells $q$ because $\lambda(q)<\frac{1-q}{2}<1-q$ implies that his capacity constraint is binding. The entrant earns $\frac{1}{4}(1-q)^{2}$ because at his highest price, he receives the residual demand $1-q$. Notice last that this latter payoff is $\Pi_{e}(q, 1)$, the limit of the equilibrium payoff obtained in Proposition 2 when product differentiation tends to zero.

\subsection{Optimal Quality Choice for the Entrant}

With the help of Proposition 2 and Lemma 2, we may now turn to the selection of the quality by the entrant given the sales restriction $q$ with the help of Figure 5.

Proposition 3 In a SPE of $\Gamma_{q}$, the entrant selects $s=1$ whenever $q \leq q^{*} \equiv 1-\frac{1}{2 \sqrt{3}}$ and $s=\frac{4}{7}$ otherwise. 
Proof Over the domain, $q>\bar{q}(s)$, where the "Laissez-Faire" equilibrium exists (see Figure 1 ), the best response in quality is given by the "Laissez-Faire" candidate $s=\frac{4}{7}$ (or $s_{e}=\bar{q}^{-1}(q)$ whenever $\frac{4}{7}$ lies outside the relevant domain). Whenever, $q \leq \bar{q}(s)$, the price equilibrium is in mixed strategies and the entrant's payoff is $\Pi_{e}(q, s)=\frac{s(1-q)^{2}}{4}$, so that the best response is obviously the top quality $s=1$; we refer to this as the "imitation" strategy. To characterize the SPE of $\Gamma_{q}$, we compare the previous profits. Solving for $\frac{1}{48}=\Pi_{e}^{*}\left(\frac{4}{7}\right)=\Pi_{e}(q, 1)=\frac{(1-q)^{2}}{4}$, we obtain the cut-off quota $q^{*} \equiv 1-\frac{1}{2 \sqrt{3}} \simeq 71 \%$.

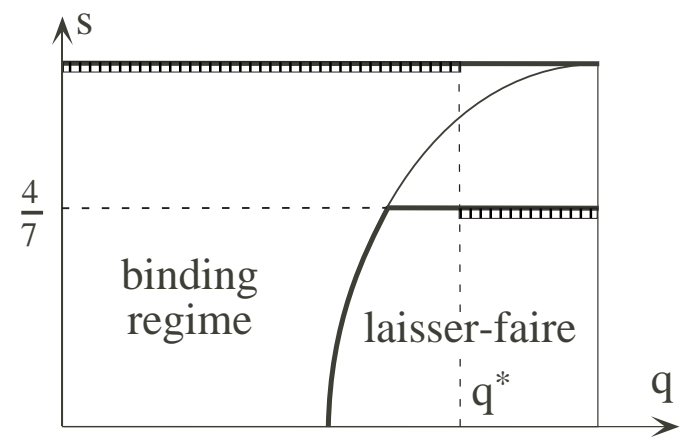

Figure 5: The quota-quality space

\subsection{Optimal Sales Restriction for the Regulator}

We identify here the welfare maximizing sales restriction. Notice first that if a regulator's objective was simply to ensure the provision of the best available quality by both firms, it would be sufficient to impose a sales restriction (SR) at any level $q \leq q^{*}(\simeq 71 \%$ of the market size). This level is often binding in the ensuing price game but is not unreasonably restrictive as it is larger than the equilibrium sales' level of the incumbent in the "Laissez-Faire" case $(\simeq 58 \%)$.

Similar to the case of the MQS, a sales restriction might trigger different entry and quality choices from the challenger; two distinct regimes must be analyzed and compared. The intuition underlying the welfare comparison is nevertheless easy to grab. Over the domain where the sales restriction induces quality imitation, a looser quota reduces industry profits as we approach the standard Bertrand equilibrium with zero profits. In other words, a looser quota generates a fiercer competition at the price stage and a greater consumer surplus. Computations show that the gain with consumer surplus dominates the loss with industry profit. Accordingly, the optimal sales restriction is the loosest compatible with quality imitation.

Proposition 4 The optimal Sales Restriction for the regulator is $q^{*}=1-\frac{1}{2 \sqrt{3}}$. 
Proof: For $q \leq q^{*}$, we know from Proposition 3 that the entrant chooses the highest quality and competition takes places in a market for a homogeneous good. In this equilibrium the incumbent profit is $\Pi_{i}(q)=q \lambda(q)$ while the entrant obtains $\Pi_{e}(q)=\frac{(1-q)^{2}}{4}$. We show in Lemma 3 of the appendix that market welfare, net of fixed cost, is $\bar{W}(q)=\frac{3}{8}+q \frac{4-q-2 \sqrt{q(2-q)}}{8}$. This function is increasing and concave in $q$. Since the "Laissez-Faire" welfare is $\frac{3}{8}$, a SR $q \leq q^{*}$ yields a greater welfare and the optimal choice is thus $q^{*}$, the highest quota compatible with $s=1$ in a SPE. Notice that welfare is $\bar{W}\left(q^{*}\right) \simeq 0.497$.

\subsection{Comparing Sales Restriction and MQS}

We can now assess the respective merits of Sales Restrictions and Minimum Quality Standards in our model of entry with sunk cost. Notice from Propositions 3 and 4 that the entrant's operating profits are exactly equal to $\frac{1}{48}$ at the optimal quota $q^{*}$ as in the Laissez-Faire case. Therefore, the presence of the entry cost $F$ does not constrain the government's possibilities, as compared to the case of a MQS policy. However, the optimal SR does not yield the first best welfare of $\frac{1}{2}$ whereas the MQS does at the limit where sunk cost is nil. Formally, we may state:

Proposition 5 For $F>\underline{F}$, a sales restriction induces a higher market welfare than a minimum quality standard.

Proof From Proposition 1, we know that the maximum welfare with a MQS is $\underline{W}\left(z^{*}(F)\right)-F$ where $\underline{W}\left(z^{*}(F)\right)$ is a decreasing function of $F$. From Proposition 4, we know that the maximum welfare with a SR is $\bar{W}\left(q^{*}\right)-F$. The cut-off is thus the solution $\underline{F} \simeq 4.76 \times 10^{-3}$ of $\underline{W}\left(z^{*}(F)\right)=$ $\bar{W}\left(q^{*}\right)$.

Notice first that the threshold is less than $1 \%$ of the maximum welfare achievable in this market. The economic intuition underlying our result is straightforward. A sales restriction relaxes price competition by inducing a less aggressive behaviour of the constrained firm, here the incumbent. Recall then that in a vertically differentiated duopoly, one firm selects a low quality in order to relax competition. However, in the presence of the sales restriction this is no longer necessary because the sales restriction is a more powerful instrument to reduce competition. The entrant thus looses any incentive to downgrade quality and both firms end up selecting a high quality. Moreover, because price competition is less fierce, equilibrium profits for any quality pair tend to be larger. There exists however a limit to the effective level of the sales restriction. If it is too loose, the entrant enjoys an extremely limited protected market and therefore prefers to differentiate optimally. The mechanism at work may therefore 
be summarized as follows: the quota alters the payoffs in the second stage in such a way that the entrant's incentive at the first stage are put in the "right" direction, i.e. quality upgrades.

This MQS mechanism on the other hand, directly constrains the firms' strategy space at the quality stage. By definition, in order to be effective, the MQS must run against firms' incentives. By leaving less room for differentiation, the MQS undermines firms' profits in equilibrium and therefore impedes entry. As shown in Proposition 5, it is only when the entry costs are negligible that the government prefers the MQS to a sales restriction. In this case indeed, the fact that operating profits sharply decrease because of a very high MQS is not a concern anymore. By contrast, the residual market power that must be left to firms in order to induce quality upgrades does not depend on $F$.

\section{Conclusion}

In vertically differentiated industries, MQS are often used to control for quality provision. Within a very simple model, we have shown that sales restrictions might be more efficient than MQS. Our formal model is quite specific, although it should be stressed that it is quite in line with the received literature on MQS. Several generalizations can be contemplated. Firstly, the introduction of positive quality costs that would be sunk before price competition do not alter our conclusion. Obviously, we do not expect minimal differentiation anymore. However, average quality bought by consumers increases and industry welfare increases as well. Similarly, our results are likely to remain valid if we do not impose any exogenous quality hierarchy between the entrant and the incumbent. ${ }^{13}$

A third avenue regards the mode of competition. As we show in the appendix, comparable conclusions are reached unde Cournot competition as well. All in all, the driver of our result is robust and is simply the intrinsic ability of quantitative restraints to relax price competition. In vertically differentiated industries, this almost immediately implies that firms do not need to relax competition by differentiating products. Accordingly, average quality may rise. Regarding quality selection, the chief merit of the sales restriction is thus quite clear: it gives to all firms an incentive to select a high quality for their products.

\section{Appendix}

Proof of Lemma 1 If quality is not costly and the incumbent sells quality $s_{i}=1$, then whenever $F \leq \frac{1}{48}$, the entrant enters and optimally differentiates by selecting quality $\frac{4}{7}$. The

\footnotetext{
${ }^{13}$ See Boccard and Wauthy (1997) for a more detailed analysis.
} 
price equilibrium of the continuation game is unique and in pure strategies.

Recall that

$$
\begin{aligned}
& D_{e}\left(p_{e}, p_{i}\right)= \begin{cases}1-\frac{p_{e}}{s} & \text { if } p_{e} \leq p_{i}-1+s \\
\frac{p_{i} s-p_{e}}{s(1-s)} & \text { if } p_{i}-1+s \leq p_{e} \leq p_{i} s \\
0 & \text { if } \quad p_{e} \geq p_{i} s\end{cases} \\
& D_{i}\left(p_{e}, p_{i}\right)= \begin{cases}1-p_{i} & \text { if } p_{i} \leq \frac{p_{e}}{s} \\
1-\frac{p_{i}-p_{e}}{1-s} & \text { if } \quad \frac{p_{e}}{s} \leq p_{i} \leq p_{e}+1-s \\
0 & \text { if } p_{i} \geq p_{e}+1-s\end{cases}
\end{aligned}
$$

and that profits are $\Pi_{e}\left(p_{i}, p_{e}\right)=p_{e} D_{e}\left(p_{i}, p_{e}\right)$ and $\Pi_{i}\left(p_{i}, p_{e}\right)=p_{i} D_{i}\left(p_{i}, p_{e}\right)$.

The solution to $\frac{\partial \Pi_{e}}{\partial p_{e}}=0$ over the range where both demands are non-negative is $\psi_{e}\left(p_{i}\right) \equiv$ $\frac{p_{i} s}{2} \leq p_{i} s$; thus, the low quality best response function is $\phi_{e}\left(p_{i}\right)=\psi_{e}\left(p_{i}\right)$. In the incumbent monopoly region $\left(p_{e}>p_{i} s\right)$, the incumbent's best response is the monopoly price $\frac{1}{2}$ which is feasible if and only if $p_{e}>\frac{s}{2}$. Otherwise, $\Pi_{i}$ is strictly increasing in the monopoly region and we always reach the duopoly region where the profit is $p_{i}\left[1-\frac{p_{i}-p_{e}}{1-s}\right]$ leading to a candidate best response $\psi_{i}\left(p_{e}\right) \equiv \frac{p_{e}+1-s}{2}$. Whenever $p_{e} \leq \frac{s(1-s)}{2-s}$ then $\psi_{i}\left(p_{e}\right) \leq \frac{p_{e}}{s}$ meaning that $\psi_{i}$ is the best response, otherwise it is the frontier price $\frac{p_{e}}{s}$ which is optimal. As we have $\frac{s(1-s)}{2-s}<\frac{s}{2}$, the (kinked) best response of firm $h$ is

$$
\phi_{i}\left(p_{e}\right)=\left\{\begin{array}{clc}
\psi_{i}\left(p_{e}\right) & \text { if } & p_{e} \leq \frac{s(1-s)}{2-s} \\
\frac{p_{e}}{s} & \text { if } & \frac{s(1-s)}{2-s} \leq p_{e} \leq \frac{s}{2} \\
\frac{1}{2} & \text { if } & \frac{s}{2} \leq p_{e}
\end{array}\right.
$$

As one can see on Figure 2 in the text p.7, the Laissez-Faire equilibrium $\left(p_{e}^{*}, p_{i}^{*}\right)=$ $\left(\frac{s(1-s)}{4-s}, \frac{2(1-s)}{4-s}\right)$ is given by the intersection of $\psi_{e}$ and $\psi_{i}$.

In the quality stage we have $\Pi_{i}(s) \equiv p_{i}^{*} D_{i}^{*}=\frac{4(1-s)}{(4-s)^{2}}$ and $\Pi_{e}(s) \equiv p_{e}^{*} D_{e}^{*}=\frac{s(1-s)}{(4-s)^{2}}$. It is a matter of calculations to check that $\Pi_{e}$ reaches its maximum for $s=\frac{4}{7}$.

Lemma 3 In $\Gamma_{q}$, market welfare, net of fixed cost, is $\bar{W}(q)=\frac{3}{8}+q \frac{4-q-2 \sqrt{q(2-q)}}{8}$.

Proof The surplus of the consumer with type $x \in[0,1]$ is best understood by separating 2 cases:

- if $x>1-q$, then $x>p_{e}$ because $p_{e} \leq \frac{1-q}{2}$. The incumbent price $p_{i}$ is the lowest with probability $F_{i}\left(p_{e}\right)$ in which case the consumer buys at the price $p_{i}$ (because $x>p_{e}>p_{i}$ and the incumbent is not constrained) so that we need to compute an expectation. 
With complementary probability, the consumer buys at the entrant, thus the surplus of consumer $x$ is

$$
H\left(x, p_{e}\right) \equiv\left(x-p_{e}\right)\left(1-F_{i}\left(p_{e}\right)\right)+\int_{\lambda(q)}^{p_{e}}\left(x-p_{i}\right) d F_{i}\left(p_{i}\right)
$$

- if $x<1-q$, the consumer is rationed by the incumbent; then either $x<p_{e}$ so that he does not buy at all, or $x>p_{e}$ and he buys from the entrant deriving a surplus of $x-p_{e}$.

Integrating with respect to the distribution of the entrant's prices, we have three cases according to the respective positions of $x$ and the upper price limit:

- if $x<\frac{1-q}{2}, W_{a}(q, x) \equiv \int_{\lambda(q)}^{x}\left(x-p_{e}\right) d F_{e}\left(p_{e}\right)$

- if $\frac{1-q}{2}<x<1-q, W_{b}(q, x) \equiv \int_{\lambda(q)}^{\frac{1-q}{2}}\left(x-p_{e}\right) d F_{e}\left(p_{e}\right)+\left(x-\frac{1-q}{2}\right)\left(1-F_{e}\left(\frac{1-q}{2}\right)\right)$

- if $1-q<x, W_{c}(q, x) \equiv \int_{\lambda(q)}^{\frac{1-q}{2}} H\left(x, p_{e}\right) d F_{e}\left(p_{e}\right)+H\left(x, \frac{1-q}{2}\right)\left(1-F_{e}\left(\frac{1-q}{2}\right)\right)$

Integrating with respect to the uniform distribution of consumers over the range of potential buyers i.e., $x \geq \lambda(q)$, we obtain the consumer surplus expression:

$$
\begin{aligned}
W_{C}(q) & \equiv \int_{\lambda(q)}^{\frac{1-q}{2}} W_{a}(q, x) d x+\int_{\frac{1-q}{2}}^{1-q} W_{b}(q, x) d x+\int_{1-q}^{1} W_{c}(q, x) d x \\
& =\frac{1}{8}+q \frac{4-3 q+2 \sqrt{q(2-q)}}{8}
\end{aligned}
$$

simplifies is an increasing and concave function. Observe that $W_{C}(1)=\frac{1}{2}$, is the market welfare at the outcome of Bertrand competition between two identical products where no consumer refrains from buying, all consumers buy the best available quality and firms capture no rent. The market welfare summing consumer surplus and producers surplus is

$$
\bar{W}(q)=W_{C}(q)+\Pi_{i}(q)+\Pi_{e}(q)=\frac{3}{8}+q \frac{4-q-2 \sqrt{q(2-q)}}{8}>\frac{3+q}{8}
$$




\section{Cournot Competition}

We address here the case where firms compete in quantity in the last stage of game. When the demands (1) and (2) are positive, we have

$$
q_{i}=1-\frac{p_{i}-p_{e}}{1-s} \quad \text { and } \quad q_{e}=\frac{p_{i} s-p_{e}}{s(1-s)}
$$

so that the inverse demands characterizing Cournot competition are given by

$$
p_{i}=1-q_{i}-q_{e} s \quad \text { and } \quad p_{e}=\left(1-q_{i}-q_{e}\right) s
$$

The best replies in quantities are immediately derived as

$$
B R_{i}^{c}\left(q_{e}\right) \equiv \frac{1-q_{e} s}{2} \text { and } B R_{e}^{c}\left(q_{i}\right) \equiv \frac{1-q_{i}}{2}
$$

The unconstrained Cournot equilibrium is thus

$$
q_{e}^{c}(s) \equiv \frac{1}{4-s} \quad \text { and } \quad q_{i}^{c}(s) \equiv \frac{2-s}{4-s} .
$$

leading to equilibrium prices

$$
p_{e}^{c}=\frac{s}{4-s} \quad \text { and } \quad p_{i}^{c}=\frac{2-s}{4-s}
$$

Notice that $q_{e}^{c}$ is increasing with $s$ while $q_{i}^{c}$ is decreasing. The entrant's profits at the Cournot

equilibrium are $\pi_{e}^{c}(s) \equiv \frac{s}{(4-s)^{2}}$ and since $\frac{\partial \pi_{e}^{c}}{\partial s}=\frac{4+s}{(4-s)^{3}}>0$, the optimal choice for the low quality firm is imitation.

\section{References}

Albano G. L. and Lizzeri A. Strategic certification and provision of quality. International Economic Review, 42(1):267-283, 2001.

Auriol E. Deregulation and quality. International Journal of Industrial Organization, 16(2): 169-194, 1998.

Boccard N. and Wauthy X. Import restraints foster minimum differentiation in vertically differentiated industries. Technical Report 9782, CORE, 1997.

Cabral C. C., Kujal P., and Petrakis E. Incentives for cost reducing innovations under quantitative import restraints. Annales d'économie et de statistique, (49-50):479-493, 1998.

Chipty T. and Witte A. D. An empirical investigation of firms responses to minimum standards regulations. Technical Report 6104, NBER, 1997. 
Choi C. J. and Shin H. S. A comment on a model of vertical product differentiation. Journal of Industrial Economics, 40(2):229-231, 1992.

Crampes C. and Hollander A. Duopoly and quality standards. European Economic Review, 39(1):71-82, 1995.

Davidson C. and Deneckere R. Long-run competition in capacity, short-run competition in price and the cournot model. RAND Journal of Economics, 17(3):404-415, 1986.

Furth D. and Kovenock D. Price leadership in a duopoly with capacity constraints and product differentiation. Journal of Economics, 57(1):1-35, 1993.

Gabszewicz J. J. and Thisse J. F. Price competition, quality and income disparities. Journal of Economic Theory, 20:340-359, 1979.

Glass A. J. Price discrimination and quality improvement. Canadian Journal of Economics, 34(2):549-569, 2001.

Kreps D. and Scheinkman J. Quantity precommitment and bertrand competition yields cournot outcomes. Bell Journal of Economics, (14):326-337, 1983.

Krishna K. Trade restrictions as facilitating practices. Journal of International Economics, 26(3-4):251-270, 1989.

Levitan R. and Shubik M. Price duopoly and capacity constraints. International Economic Review, 13:111-122, 1972.

Lutz S., Lyon T. P., and Maxwell J. W. Quality leadership when regulatory standards are forthcoming. Journal of Industrial Economics, 48(3):331-348, 2000.

Maxwell J. W. Minimum quality standards as a barrier to innovation. Economics Letters, 58 (3):355-360, 1998.

Mussa M. and Rosen S. Monopoly and product quality. Journal of Economic Theory, (18): 301-317, 1978.

Rhoades D. L. and Waguespack B. Judging a book by it's cover: the relationship between service and safety quality in us national and regional airlines. Journal of Air Transport Management, 6(2):87-94, 2000.

Ronnen U. Minimum quality standards, fixed costs, and competition. RAND Journal of Economics, 22(4):490-504, 1991. 
Scarpa C. Minimum quality standards with more than two firms. International Journal of Industrial Organization, 16(5):665-676, 1998.

Sheshinski E. Price, quality and quantity regulation in monopoly situations. Economica, 43 (170):127-137, 1976.

Tirole J. The theory of industrial organization. MIT press, 1988.

Valletti T. M. Minimum quality standards under cournot competition. Journal of Regulatory Economics, 18(3):235-245, 2000. 


\section{Recent titles \\ CORE Discussion Papers}

2009/14. Gauthier de MAERE d'AERTRYCKE and Yves SMEERS. The valuation of power futures based on optimal dispatch.

2009/15. Thierry BRECHET, Tsvetomir TSACHEV and Vladimir M. VELIOV. Prices versus quantities in a vintage capital model.

2009/16. François VANDERBECK and Laurence A. WOLSEY. Reformulation and decomposition of integer programs.

2009/17. Marc FLEURBAEY, Erik SCHOKKAERT and Koen DECANCQ. What good is happiness?

2009/18. David DE LA CROIX and Michel LUBRANO. The tradeoff between growth and redistribution: ELIE in an overlapping generations model.

2009/19. Thierry BRECHET and Fabien PRIEUR. Can education be good for both growth and the environment?

2009/20. Giacomo SBRANA and Andrea SILVESTRINI. What do we know about comparing aggregate and disaggregate forecasts?

2009/21. Marc GERMAIN, Henry TULKENS and Alphonse MAGNUS. Dynamic core-theoretic cooperation in a two-dimensional international environmental model.

2009/22. Claude D'ASPREMONT and Rodolphe DOS SANTOS FERREIRA. Household behavior and individual autonomy.

2009/23. Helmuth CREMER, Philippe DE DONDER and Pierre PESTIEAU. Education and social mobility.

2009/24. Maria Eugenia SANIN and Francesco VIOLANTE. Understanding volatility dynamics in the EU-ETS market: lessons from the future.

2009/25. Marco DI SUMMA and Laurence A. WOLSEY. Lot-sizing with stock upper bounds and fixed charges.

2009/26. Johanna M.M. GOERTZ and François MANIQUET. On the informational efficiency of simple scoring rules.

2009/27. Jean GABSZEWICZ, Ornella TAROLA and Skerdilajda ZANAJ. On uncertainty when it affects successive markets.

2009/28. Jerzy A. FILAR, Jacek B. KRAWCZYK and Manju AGRAWAL. On production and abatement time scales in sustainable development. Can we loosen the sustainability screw?

2009/29. María Eugenia SANIN and Skerdilajda ZANAJ. Clean technology adoption and its influence on tradeable emission permit prices.

2009/30. Antoine BOMMIER, Marie-Louise LEROUX and Jean-Marie LOZACHMEUR. On the public economics of annuities with differential mortality.

2009/31. Gilles GRANDJEAN, Ana MAULEON and Vincent VANNETELBOSCH. Connections among farsighted agents.

2009/32. Axel GAUTIER and Xavier WAUTHY. On the nature of price competition under universal service obligations: a note.

2009/33. Santanu S. DEY and Laurence A. WOLSEY. Constrained infinite group relaxations of MIPs.

2009/34. Jean-François MAYSTADT and Philip VERWIMP. Winners and losers among a refugeehosting population.

2009/35. Pierre DEHEZ. Allocation of fixed costs and the weighted Shapley value.

2009/36. Sabien DOBBELAERE, Roland Iwan LUTTENS and Bettina PETERS. Starting an R\&D project under uncertainty.

2009/37. Carlotta BALESTRA and Davide DOTTORI. Aging society, health and the environment.

2009/38. Alain PHOLO BALA. Urban concentration and economic growth: checking for specific regional effects.

2009/39. Alain PHOLO BALA. Gates, hubs and urban primacy in Sub-Saharan Africa.

2009/40. Nicolas BOCCARD. On efficiency, concentration and welfare.

2009/41. Taoufik BOUEZMARNI, Jeroen V.K. ROMBOUTS and Abderrahim TAAMOUTI. A nonparametric copula based test for conditional independence with applications to Granger causality. 


\section{Recent titles}

\section{CORE Discussion Papers - continued}

2009/42. Josez KONINGS and Hylke VANDENBUSSCHE. Antidumping protection hurts exporters: firm-level evidence from France.

2009/43. Pierre PESTIEAU and Uri M. POSSEN. Retirement as a hedge.

2009/44. Santanu S. DEY and Laurence A. WOLSEY. Lifting group inequalities and an application to mixing inequalities.

2009/45. Jean CAVAILHES, Pierre FRANKHAUSER, Dominique PEETERS and Isabelle THOMAS. Residential equilibrium in a multifractal metropolitan area.

2009/46. Daisuke OYAMA, Yasuhiro SATO, Takatoshi TABUCHI and Jacques-François THISSE. On the impact of trade on industrial structures: The role of entry cost heterogeneity.

2009/47. Ken-Ichi SHIMOMURA and Jacques-François THISSE. Competition among the big and the small.

2009/48. Frédéric BABONNEAU, Yurii NESTEROV AND Jean-Philippe VIAL. Design and operations of gas transmission networks.

2009/49. Olivier BOS. How lotteries outperform auctions for charity.

2009/50. Xavier WAUTHY and Nicolas BOCCARD. Entry accommodation under multiple commitment strategies: judo economics revisited.

2009/51. Joachim GAHUNGU and Yves SMEERS. Multi-assets real options.

2009/52. Nicolas BOCCARD and Xavier WAUTHY. Regulating quality by regulating quantity: a case against minimum quality standards.

\section{Books}

Public goods, environmental externalities and fiscal competition: 22 selected papers in public economics by Henry Tulkens, edited and introduced by Parkash Chander, Jacques Drèze, C. Knox Lovell and Jack Mintz, Springer, Boston 2006 (588 pp.).

V. GINSBURGH and D. THROSBY (eds.) (2006), Handbook of the economics of art and culture. Amsterdam, Elsevier.

J. GABSZEWICZ (ed.) (2006), La différenciation des produits. Paris, La découverte.

L. BAUWENS, W. POHLMEIER and D. VEREDAS (eds.) (2008), High frequency financial econometrics: recent developments. Heidelberg, Physica-Verlag.

P. VAN HENTENRYCKE and L. WOLSEY (eds.) (2007), Integration of AI and OR techniques in constraint programming for combinatorial optimization problems. Berlin, Springer.

P-P. COMBES, Th. MAYER and J-F. THISSE (eds.) (2008), Economic geography: the integration of regions and nations. Princeton, Princeton University Press.

J. HINDRIKS (ed.) (2008), Au-delà de Copernic: de la confusion au consensus ? Brussels, Academic and Scientific Publishers.

J-M. HURIOT and J-F. THISSE (eds) (2009), Economics of cities. Cambridge, Cambridge University Press.

\section{CORE Lecture Series}

C. GOURIÉROUX and A. MONFORT (1995), Simulation Based Econometric Methods.

A. RUBINSTEIN (1996), Lectures on Modeling Bounded Rationality.

J. RENEGAR (1999), A Mathematical View of Interior-Point Methods in Convex Optimization.

B.D. BERNHEIM and M.D. WHINSTON (1999), Anticompetitive Exclusion and Foreclosure Through Vertical Agreements.

D. BIENSTOCK (2001), Potential function methods for approximately solving linear programming problems: theory and practice.

R. AMIR (2002), Supermodularity and complementarity in economics.

R. WEISMANTEL (2006), Lectures on mixed nonlinear programming. 